International Journal of Biomedical Engineering and Science (IJBES), Vol. 4, No. 2, April 2017

\title{
EFFECT OF NEGATIVE ANGLE CANNULATION DURING CARDIOPULMONARY BYPASS - A COMPUTATIONAL FLUID DYNAMICS STUDY
}

\author{
Wael Mokhtar ${ }^{1}$, Kyle A. Dinger ${ }^{2}$, Chetan Madagi ${ }^{2}$, and Md Razib Hossain ${ }^{2}$ \\ School of Engineering, Grand Valley State University, Grand Rapids, USA
}

\begin{abstract}
Creation of emboli in the aortic root and changes in flow distribution between supra-aortic arteries and descending aorta can lead to stroke and perfusion related tissue damage during cardiopulmonary bypass. A thorough understanding of how the angle of cannulation affects the overall success of cardiopulmonary bypass during cannulation of the ascending aorta is needed. Previous simulation research has observed the effect of outflow cannula position by changing the location of the cannulation site to the subclavian artery and other vessels, as well as positions for innovative cannula designs. The purpose of this study is to evaluate the success of the procedure while using a straight cannula, modulating the angle of cannulation below horizontal in the frontal plane. A simplified geometry of the aorta was used. The success of the procedure was quantified by observing wall shear stress, normal stress, intra-fluid shear stress, and flow distribution. A numerical study was performed to solve the Reynolds Averaged Naiver Stokes governing equations, which were used in conjunction with a constant density fluid to simulate blood, and a realizable two-layer $k$-E turbulence model.
\end{abstract}

\section{KEYWORDS}

Cardiopulmonary Bypass, Cannulation Angle, Blood Flow Simulation, Computational Fluid Dynamics

\section{INTRODUCTION}

Cardiopulmonary bypass is a routine medical procedure that allows the heart to be stopped while still delivering oxygenated blood to the body tissues. There are many variables involved that determine the degree of success of the procedure. If the ascending aorta is being cannulated, the angle of which the cannula is introduced to the major vessel can mean the difference between a successful procedure and a procedure that results in a range of post-operative disorders, related to the nature of the perfusion.

Cardiopulmonary bypass (CPB) has been used for decades with success for most patients undergoing the procedure. However, there is evidence that CPB causes harm to some, including stroke, brain damage, tissue damage and inflammation, and organ failure [1]. Major factors that influence the success of the CPB procedure are shear stress and pressure on the walls of the aorta that lead to mobilization of an atherosclerotic embolism, stagnant blood flow that could lead to thrombotic embolism, flow distribution that could lead to poor end organ perfusion, and high intra-fluid shear stress that leads to hemolysis.

DOI: 10.5121/ijbes.2017.4201 
International Journal of Biomedical Engineering and Science (IJBES), Vol. 4, No. 2, April 2017

The position of the cannula during $\mathrm{CPB}$ is a decision made on a case by case basis. Severe atherosclerosis in the aorta can lead surgeons to have to select a different vessel from the ascending aorta as a cannulation site. Furthermore, as the style of cannula changes, different cannulations sites and orientations may be necessary, as the outflow takes on different characteristics[2]. In this case, a straight outflow cannula was used and a cannulation site, 1 inch inferior to the brachiocephalic trunk along the right side of the aortic arch was held constant for the entirety of the study.

\subsection{Procedural Complications}

The post-operative disorders of concern are synthesis of either thrombotic or atherosclerotic embolism, damage of vascular tissues, hemolysis of the red blood cells, and retro perfusion of any of the supra aortic arteries. The major fluid mechanics principles that contribute to these disorders are low fluid velocity in the volume[3], high wall shear stress on the vascular wall, high normal pressure on the vascular wall, and high intra-fluid shear stress respectively.

As blood flows through the cannula and is reintroduced into the ascending aorta, the flow structure changes. Large scale turbulence develops which causes the overall velocity of the flow to reduce. In areas in the aorta where the flow is not flowing freely, such as the aortic root, the lower velocity flow can lead to coagulation and thus the creation of a blood borne thrombotic embolism.

In patients with diagnosis of atherosclerosis, there are deposits of calcified cholesterol that line the inside of the blood vessels. The shear stress imposed on the vessel walls due to the viscous nature of blood flow can cause these deposits to separate from the vessel wall, becoming blood borne atherosclerotic embolisms.

Wall shear stress, defined as pressure causing a force parallel with the surface of the vessel due to viscous flow, is known to be a contributing factor to atherosclerosis. Wall shearstress is known to cause a "sandblasting" effect on existing atherosclerotic vessels. The result of that "sandblasting" is to increase the likelihood of disturbing the calcification and potentially causing an embolism. This is increasingly significant when considering the disturbance that could have arose from clamping the ascending aorta to begin the procedure [4]These atherosclerotic emboli can lead to obstructed blood flow causing stroke and brain damage[5].

Normal stress due to flow stagnation on an area of the aorta could create pressure damage to the existing calcification. In conjunction with wall shear stresses, increase the likelihood of embolism mobilization.

The cells that make up the lining of the blood vessels are susceptible to damage from high normal pressure due to incident flow "jetting" the inside of the vessel. In this application, the flow from the cannula stagnating on the inside of the aorta is an example of this.

One of the major goals for cardiopulmonary bypass is to perfuse the body in a manner similar to normal cardiac function. If the distribution of oxygenated blood during cardiopulmonary bypass is different, it is possible to cause injury. For instance, if the cannula placement induces high velocity flow below any of the entrances to the supra aortic arteries, it is possible that flow will induce a Venturi effect, resulting in flow reversal in the brachiocephalic trunk. The lack of 
oxygenated blood reaching the brain tissue through that vessel could result in damage to the tissue and corresponding cognitive damage[6].

\subsection{Computational Fluid Dynamics Representation}

Stagnant flow patterns in the aorta allow for the synthesis of thrombotic embolism. In the context of CPB one of the major areas of concern is the root of the ascending aorta where flow can lose velocity.

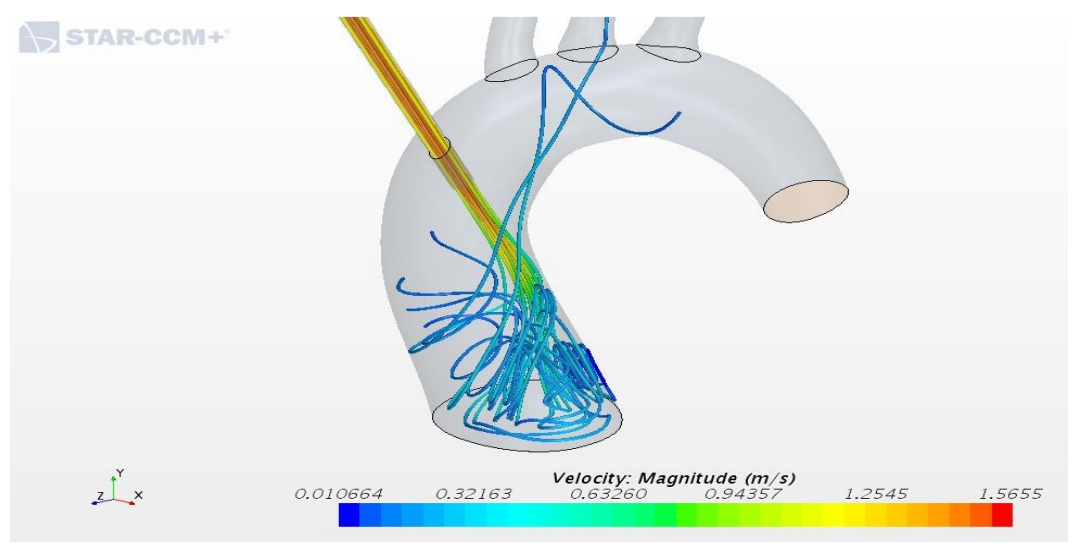

Figure 1. CPB case showing loss of fluid velocity in the aortic root in the event of direct injection

Figure 1 shows how even when the blood is injected directly into the ascending aorta a large amount of its velocity is lost to turbulence at the base of the aortic root. That slow-moving blood increases the risk for thrombosis in the CPB circuit [7].

During CPB depending on the cannulation site and angle of incidence, the procedure can induce retrograde perfusion in the brachiocephalic trunk [8]. Flow reversal in the artery that delivers oxygenated blood to the brain is a major contributor to brain damage during CPB.

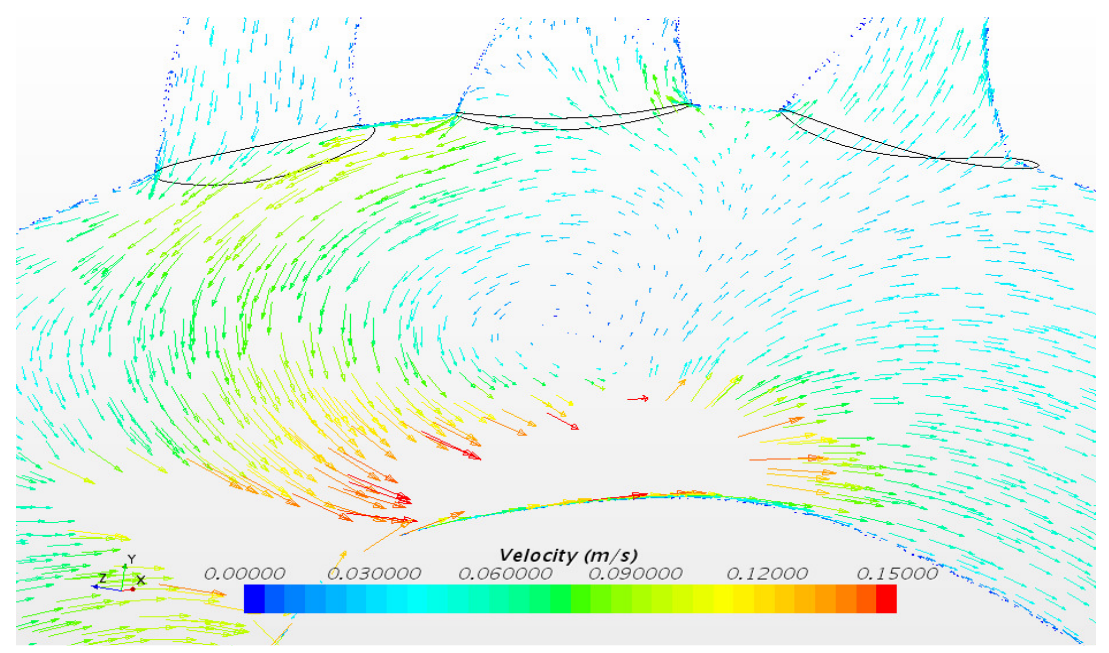

Figure.2 Perfusion case showing retrograde perfusion of BCT and LCCA 
Figure 2 shows a possible perfusion case when cannulating in the ascending aorta. High velocity flow below any of the supra aortic arteries leads to a low-pressure area at the opening; this leads to flow reversal at that outlet. An evenly distributed high-pressure environment is necessary to ensure proper flow direction and distribution.

As CPB is meant to provide a comparably similar flow distribution to normal cardiac function, it was necessary to get an understanding of what normal cardiac blood-flow distributions look like. Table 1 shows the flow distribution values gathered from the European Society of Radiology.

Table 1: Normal cardiac function blood flow distribution numbers [9]

\begin{tabular}{|l|l|l|}
\hline \multicolumn{3}{|l|}{ Real Blood Flow (European Cardiovascular Group) } \\
\hline Artery & Vdot (1/min) & \% of total flow \\
\hline ASC & 6.67 & $\mathbf{1 0 0 \%}$ \\
\hline BCA & 1.08 & $\mathbf{1 6 . 2 \%}$ \\
\hline LCA & 0.45 & $\mathbf{6 . 7 \%}$ \\
\hline LSA & 0.5 & $\mathbf{7 . 5 \%}$ \\
\hline ARC & 4.58 & $\mathbf{6 8 . 7 \%}$ \\
\hline
\end{tabular}

Lastly, large areas of viscous shear stress in the blood itself can cause damage to the red blood cells. The result of large amounts of hemolysis is increased levels of potentially harmful iron and urea in the blood stream.

\section{NUMERICAL PROCEDURE}

The simulations were completed using SolidWorks 2016 to generate the CAD and STAR CCM+ v11.04 to perform the CFD studies.

\subsection{Geometric Model and Importing to STAR CCM+}

A geometrically simple model was prepared in SolidWorks. The model included the ascending aorta, aortic arch with supra aortic arteries, and the descending aorta. The supra aortic arteries were left short in the CAD model, and the model was exported as an IGES file. The IGES file was imported as a surface mesh into STAR CCM+. The resulting geometry served as the fluid region.

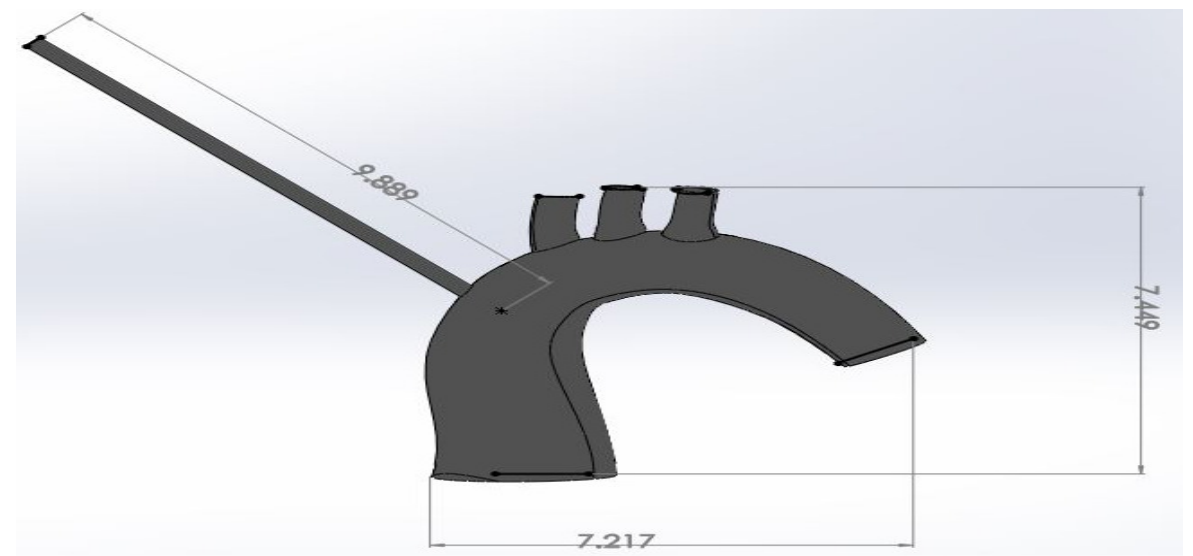

Figure 3. Overall dimensions of aorta CAD (inches) 
International Journal of Biomedical Engineering and Science (IJBES), Vol. 4, No. 2, April 2017

Table 2. Outlet Dimensions for the CAD data

\begin{tabular}{|c|c|}
\hline Outlet & Diameter $(\mathbf{m m})$ \\
\hline Ascending Aorta & 80.043 \\
\hline Brachiocephalic Trunk & 17.928 \\
\hline Left Common Carotid Artery & 14.937 \\
\hline Left Subclavian Artery & 14.646 \\
\hline Descending Aorta & 33.765 \\
\hline Cannula & 8.000 \\
\hline
\end{tabular}

\subsection{Meshing}

The meshing parameters used were surface wrapper, polyhedral mesher, surface remesher, and extruder. The wrapper was used to ensure that any discontinuities in the geometry would not disrupt the meshing of the volume. The polyhedral mesher was the best choice for the smooth asymmetric walls of the aorta and allowed the use of the extruder.

To limit numerical error in the aortic arch, the supra aortic arteries were extended. That brought the surfaces with the pressure outlet boundary condition, signifying the continuation of the artery, further away from the arch. The extruder was set to extrude a 4 in constant profile volume from the existing surface. This was split into 50 layers of constant thickness during the meshing process.

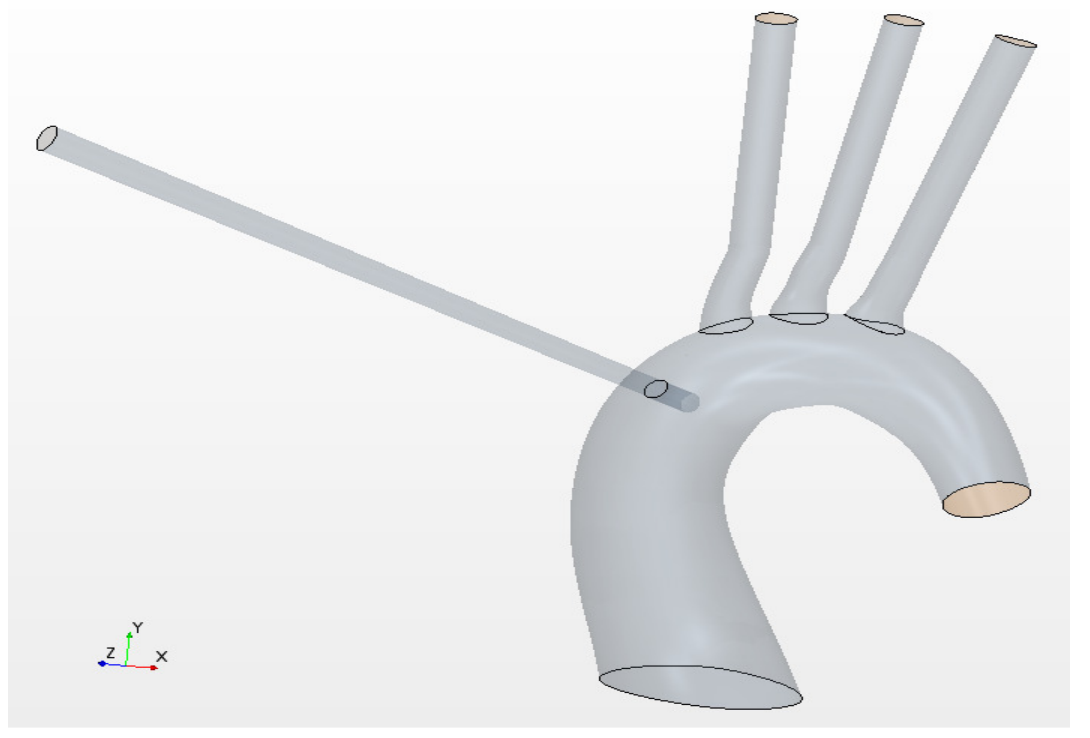

Figure 4. Volume meshed geometry showing the extrusion of the supra-aortic arteries

The final surface mesh was comprised of 374606 faces and 1243 edges. The final volume mesh was comprised of 6,779,394 cells, 32,250,815 interior faces, and 20,678,612 vertices. 
International Journal of Biomedical Engineering and Science (IJBES), Vol. 4, No. 2, April 2017

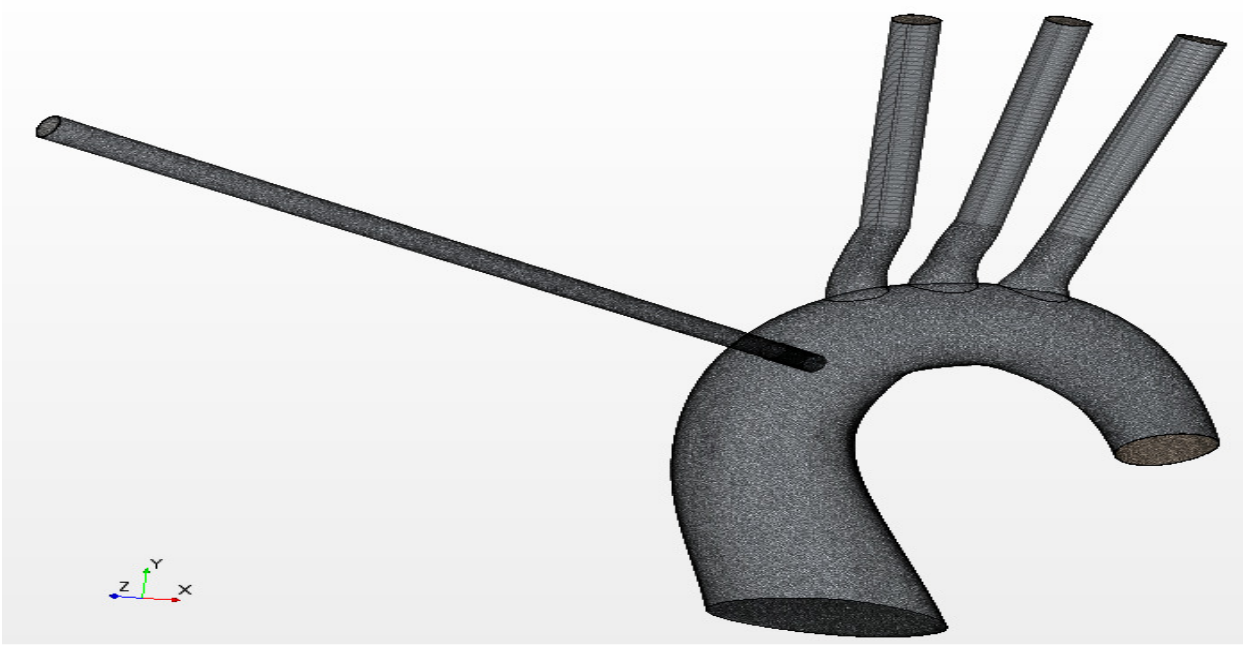

Figure 5. Total geometry showing overall mesh density

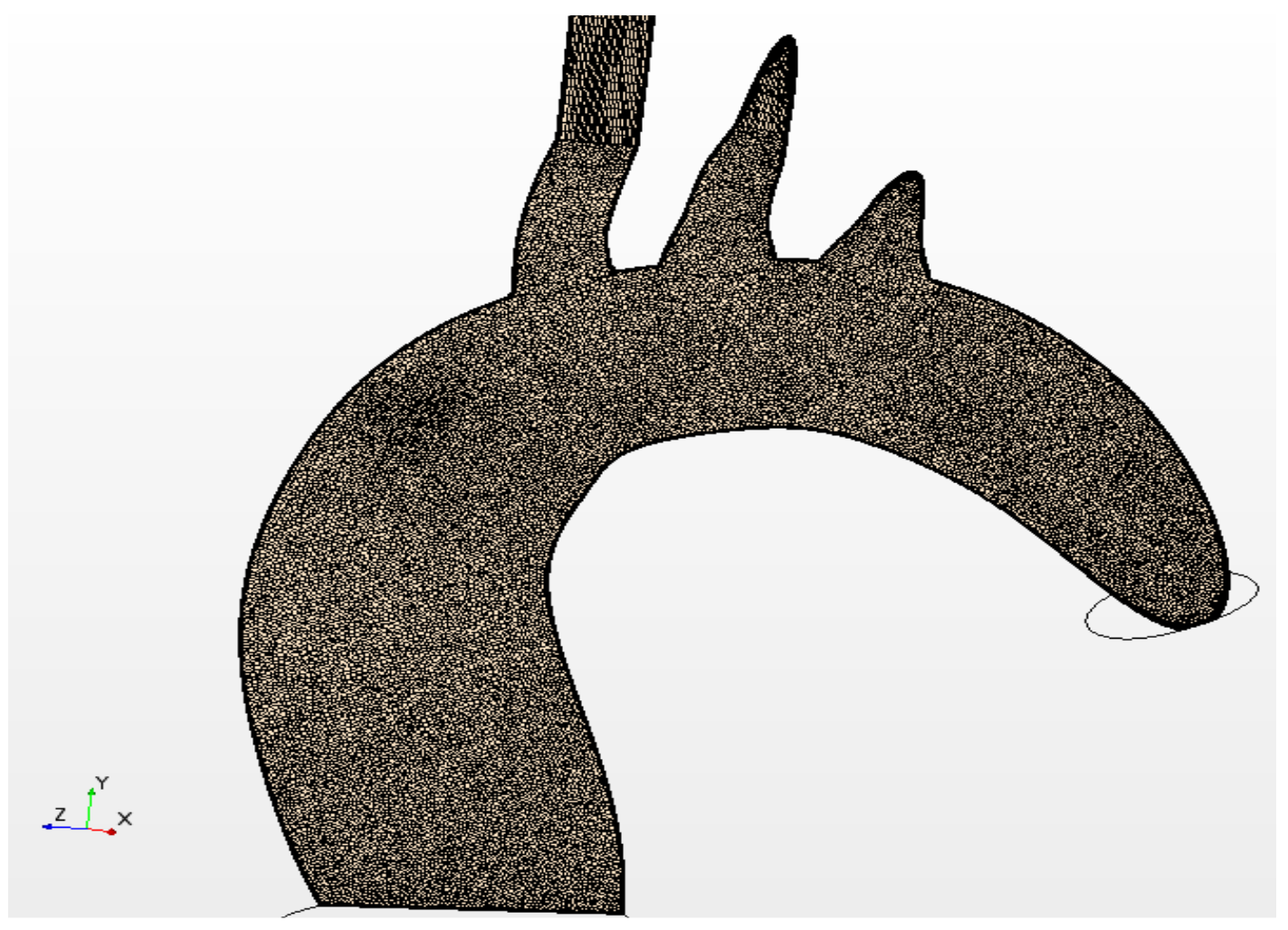

Figure 6. Section plane geometry showing mesh density in the aortic arch and entrances to the supra-aortic arteries 
International Journal of Biomedical Engineering and Science (IJBES), Vol. 4, No. 2, April 2017

\subsection{Boundary Conditions}

For the cannula simulations, the ascending aorta was treated as a wall. This simulated the effect of clamping the aorta to separate the aorta from the heart. The end of the cannula external to the aorta was treated as a mass flow inlet set to a constant value of $0.068 \mathrm{~kg} / \mathrm{s}$ which corresponds to roughly $3.7 \mathrm{l} / \mathrm{min}$ volumetric flow rate of blood.

The outlets for the supra aortic arteries and the descending aorta were treated as pressure outlets, but constant resistive pressures were applied at each outlet to better represent the human body. This was done by simulating normal human cardiac function and iteratively changing the pressure values of the outlets until the distribution matched the values found by T. Mueller et al within 5\% [9].

\subsection{Physics Conditions}

The system was modeled as a three-dimensional steady state study. The blood was modeled as water and the density was modified to $1101.45 \mathrm{~kg} / \mathrm{m}^{3}$ to match that of blood.

Turbulence was modeled using the k- $\varepsilon$ model. The realizable two-layer k- $\varepsilon$ turbulence model provides new turbulent viscosity equations and new transport equations which allow the model to better predict flows involving rotation. The two-layer portion of the model separates the computation into two layers; a layer near the wall boundary, and the layer away from the wall boundary.

\subsection{Testing Levels and Completion Criterion}

The simulations were performed with the cannula insertion angle starting at $60^{\circ}$ below horizontal and angled upward in $15^{\circ}$ increments to $0^{\circ}$. Each of the simulations were then post-processed and stored.

\section{RESULTS AND DISCUSSION}

The simulations were completed using SolidWorks 2016 to generate the CAD and STAR CCM+ v11.04 to perform the CFD studies.

\subsection{FlowStructures and Distributions}

Successful cardiopulmonary bypass produces flow distributions that closely resemble that of normal cardiac function. Furthermore, smooth helical flow is desired in the ascending aorta to create a uniform cross section of pressure prior to the supra aortic arteries.

The $60^{\circ}, 45^{\circ}$, and $30^{\circ}$ simulations produced smooth helical flow structures in the ascending aorta. The $45^{\circ}$ case produced the best results, as the flow struck the inner surface of the aorta, rebounded off the bottom of the ascending aorta and developed reasonably helical flow upward. 
International Journal of Biomedical Engineering and Science (IJBES), Vol. 4, No. 2, April 2017

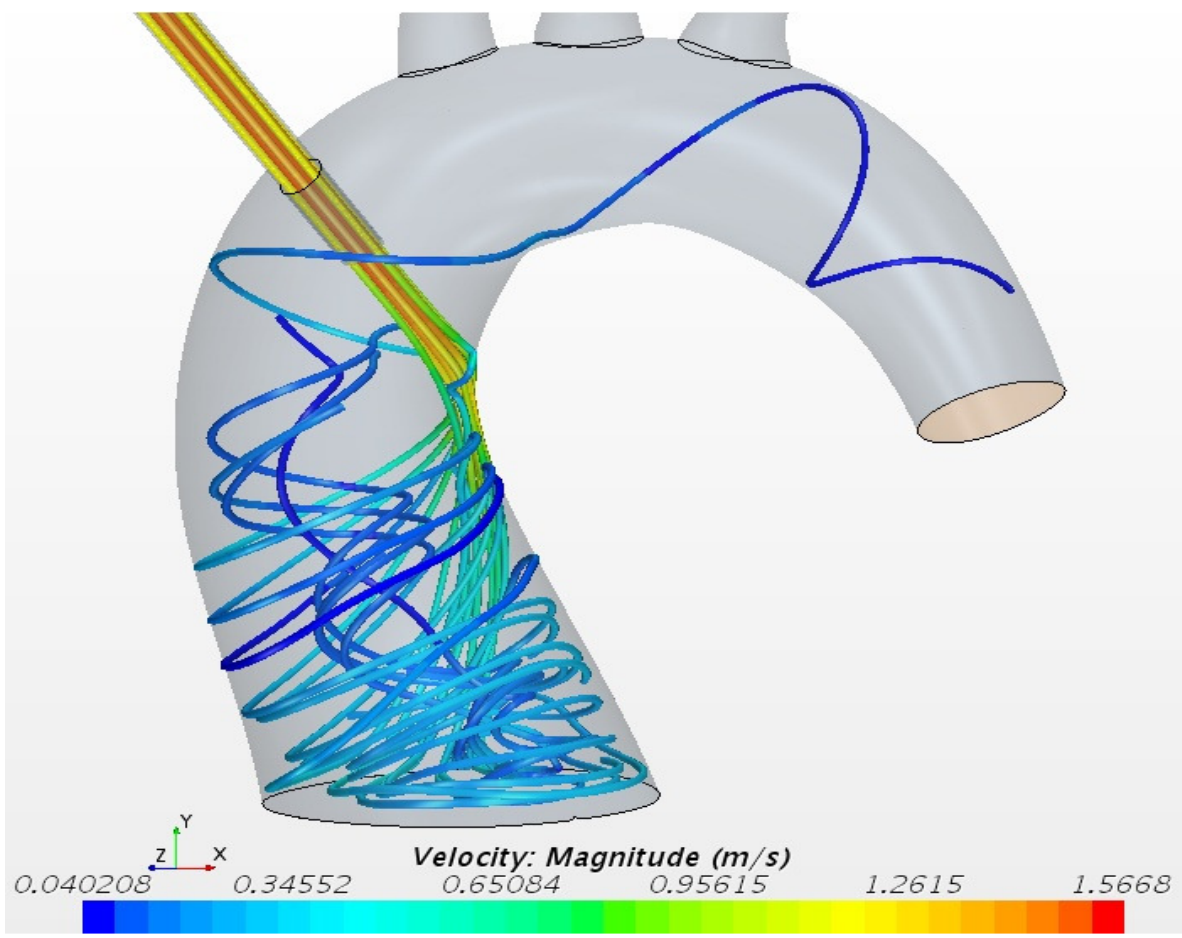

Figure $7.45^{\circ}$ case showing flow structure and fluid velocity from cannula

Whereas the $60^{\circ}$ and $30^{\circ}$ case showed issues with flow stagnating in the root of the ascending aorta and some erratic flow injecting directly into the aortic arch, respectively.

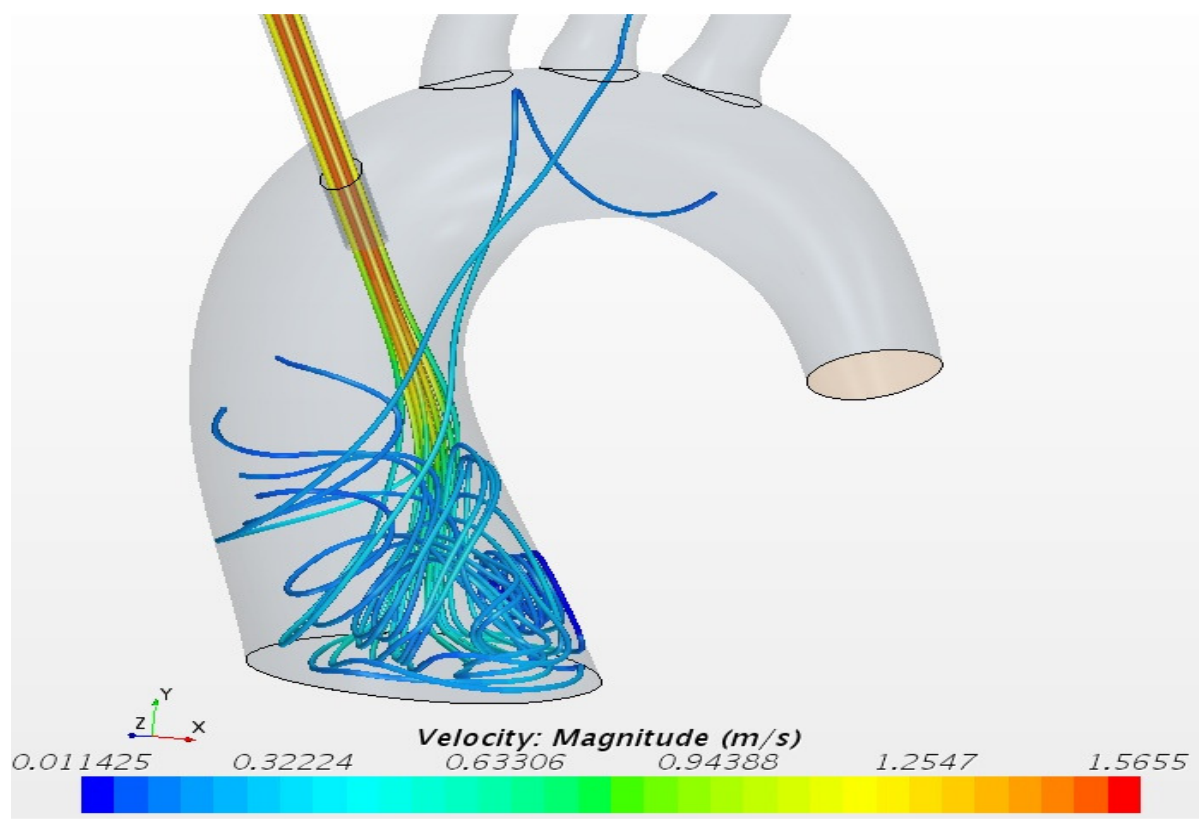

Figure $8.60^{\circ}$ case showing flow stagnation in aortic root 
International Journal of Biomedical Engineering and Science (IJBES), Vol. 4, No. 2, April 2017

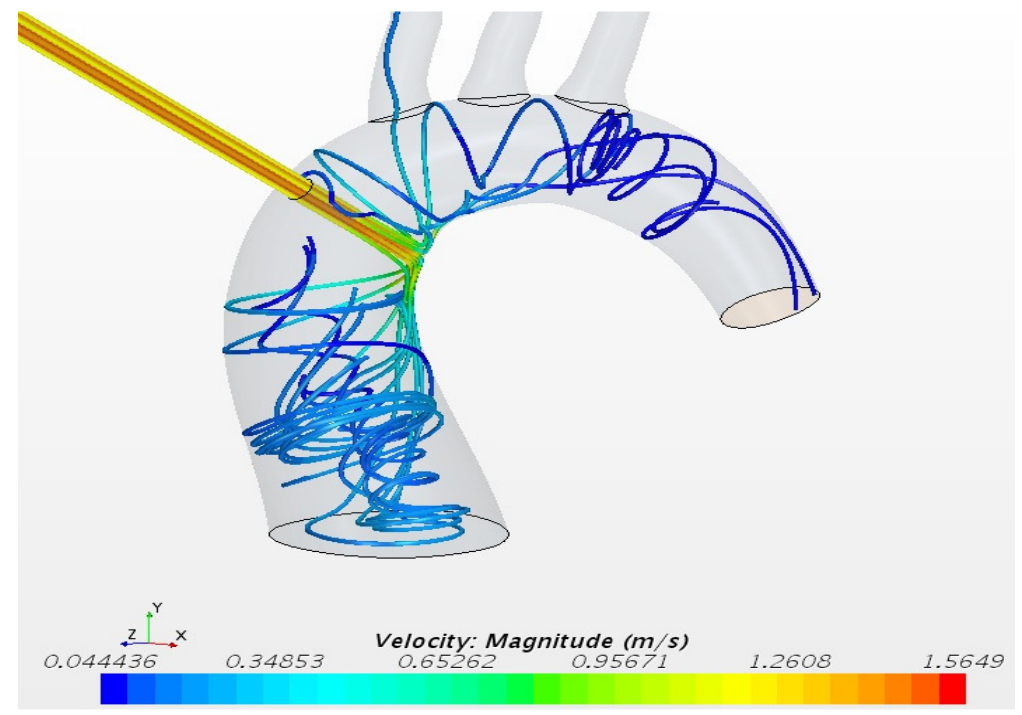

Figure $9.30^{\circ}$ case showing erratic flow patterns into the aortic arch

The $15^{\circ}$ and $0^{\circ}$ simulations resulted in major deviations from the expected flow structure, figures depicting those can be found in Appendix A.

The distribution of flow can be found in Table $3.60^{\circ}, 45^{\circ}$, and $30^{\circ}$ produced results absent of retrograde perfusion. However, $60^{\circ}$ and $30^{\circ}$ can be seen to have deviations of $22 \%$ and $27 \%$ respectively. $15^{\circ}$ and $0^{\circ}$ indicate retrograde perfusion in the brachiocephalic trunk. That flow reversal could manifest as brain damage due to poor perfusion of the brain.

Table 3. Blood flow distribution as a function of cannulation angle

\begin{tabular}{|c|c|c|c|c|c|c|c|c|c|c|}
\hline \multirow{2}{*}{$\frac{2}{2}$} & \multicolumn{2}{|c|}{$60^{\circ}$} & \multicolumn{2}{|c|}{$45^{\circ}$ (Best Case) } & \multicolumn{2}{|c|}{$30^{\circ}$} & \multicolumn{2}{|c|}{$\begin{array}{c}15^{\circ} \\
\text { (Retrograde } \\
\text { Perfusion) }\end{array}$} & \multicolumn{2}{|c|}{$\begin{array}{c}0^{\circ} \text { (Retrograde } \\
\text { Perfusion) }\end{array}$} \\
\hline & $\begin{array}{l}\text { Mass } \\
\text { Flow } \\
(\mathrm{g} / \mathrm{s})\end{array}$ & $\begin{array}{c}\% \\
\text { Disc. } \\
\text { With } \\
\text { Real }\end{array}$ & $\begin{array}{l}\text { Mass } \\
\text { Flow } \\
(\mathrm{g} / \mathrm{s})\end{array}$ & $\begin{array}{c}\% \\
\text { Disc. } \\
\text { With } \\
\text { Real }\end{array}$ & $\begin{array}{l}\text { Mass } \\
\text { Flow } \\
(\mathrm{g} / \mathrm{s})\end{array}$ & $\begin{array}{c}\% \\
\text { Disc. } \\
\text { With } \\
\text { Real }\end{array}$ & $\begin{array}{l}\text { Mass } \\
\text { Flow } \\
(\mathrm{g} / \mathrm{s})\end{array}$ & $\begin{array}{c}\% \\
\text { Disc. } \\
\text { With } \\
\text { Real }\end{array}$ & $\begin{array}{l}\text { Mass } \\
\text { Flow } \\
(\mathrm{g} / \mathrm{s})\end{array}$ & $\begin{array}{c}\% \\
\text { Disc. } \\
\text { With } \\
\text { Real }\end{array}$ \\
\hline $\begin{array}{l}\mathrm{B} \\
\mathrm{C}\end{array}$ & 17.2 & $9 \%$ & 9.3 & $-3 \%$ & $\begin{array}{c}0.017 \\
7\end{array}$ & $10 \%$ & -6.5 & $-26 \%$ & -2.5 & $-20 \%$ \\
\hline $\begin{array}{l}\mathrm{L} \\
\mathrm{C}\end{array}$ & 17.3 & $19 \%$ & 4.7 & $0 \%$ & 12.8 & $12 \%$ & 1.9 & $-4 \%$ & 6.5 & $3 \%$ \\
\hline $\begin{array}{l}\mathrm{L} \\
\mathrm{S}\end{array}$ & 1.6 & $-5 \%$ & 4.7 & $-1 \%$ & 8.9 & $6 \%$ & 7.5 & $4 \%$ & 29.4 & $36 \%$ \\
\hline $\begin{array}{l}\mathrm{D} \\
\mathrm{A}\end{array}$ & 31.8 & $-22 \%$ & 49.3 & $4 \%$ & 28.7 & $-27 \%$ & 64.9 & $27 \%$ & 34.7 & $-18 \%$ \\
\hline $\begin{array}{l}\mathrm{A} \\
\mathrm{A}\end{array}$ & 0.0 & $\mathrm{n} / \mathrm{a}$ & 0.0 & $\mathrm{n} / \mathrm{a}$ & 0.0 & $\mathrm{n} / \mathrm{a}$ & 0.0 & $\mathrm{n} / \mathrm{a}$ & 0.0 & $\mathrm{n} / \mathrm{a}$ \\
\hline $\begin{array}{l}\mathrm{C} \\
\mathrm{A} \\
\mathrm{N}\end{array}$ & -68.0 & $\mathrm{n} / \mathrm{a}$ & -68.0 & $\mathrm{n} / \mathrm{a}$ & -68.0 & $\mathrm{n} / \mathrm{a}$ & -68.0 & $\mathrm{n} / \mathrm{a}$ & -68.0 & $\mathrm{n} / \mathrm{a}$ \\
\hline
\end{tabular}


International Journal of Biomedical Engineering and Science (IJBES), Vol. 4, No. 2, April 2017

\subsection{Wall Shear Stress}

Wall shear stress is the result of viscous flow with respect to a fixed surface. In this instance the blood flow over the surface of the aorta. The resulting wall shear stress contributes to the "sandblasting" effect of potential calcification on the inner walls of the aorta. The weakening of the surface of those deposits increases the likelihood of fatty embolism mobilization, by breaking a portion of the deposit away from the vessel wall.

The $60^{\circ}$ case had the lowest levels of wall shear stress at $4 \mathrm{~Pa}$, while the $15^{\circ}$ case had the highest levels at $20 \mathrm{~Pa}$.

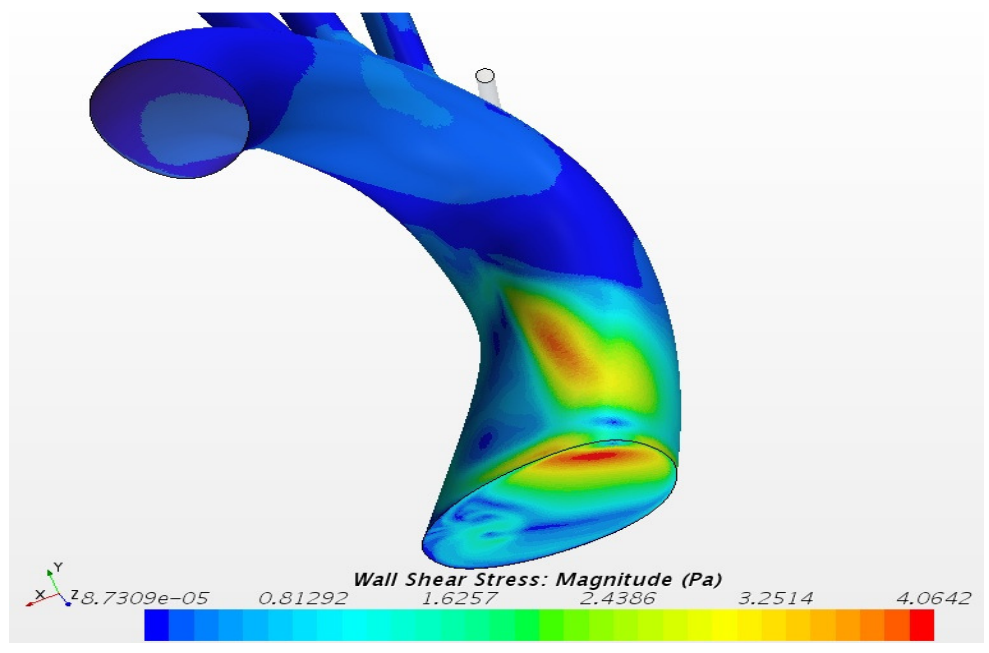

Figure $10.60^{\circ}$ case wall shear stress plot onto aorta walls

The $45^{\circ}$ and $30^{\circ}$ cases had increases in wall shear stress, at $14 \mathrm{~Pa}$ and $19 \mathrm{~Pa}$ respectively. In those instances, the areas most affected are the portions of the aorta around where the blood flow is striking.

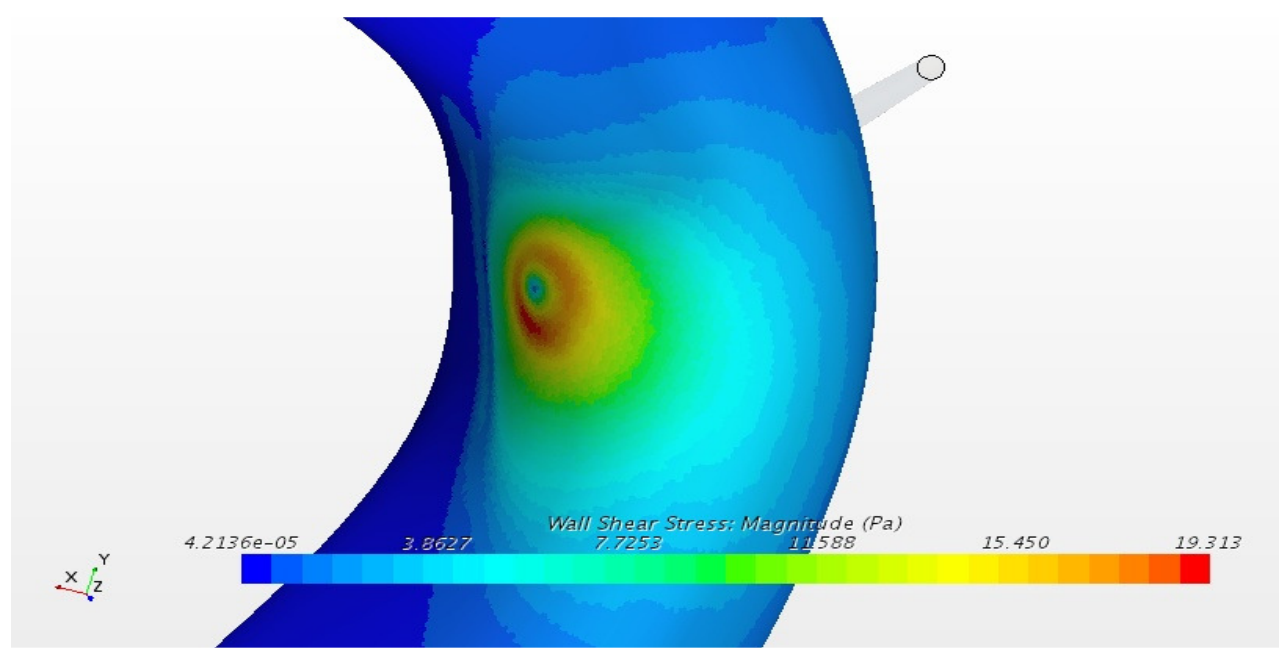

Figure $11.30^{\circ}$ case wall shear stress plot onto aorta walls 
Figure $x+3$ shows how the blood flow strikes at the central area of the arch and then as it diffuses outward, causes areas of increased wall shear stress.

\subsection{Hemolysis}

The intra-fluid shear stresses were analyzed and showed that in the $45^{\circ}, 30^{\circ}$, and $15^{\circ}$ simulations there was a risk of hemolysis. A small area on the aorta at the stagnation point of blood flow showed an isosurface that met the maximum stress level in the fluid. $600 \mathrm{~Pa}$ was the stress level that was considered damaging to the red blood cells [10].

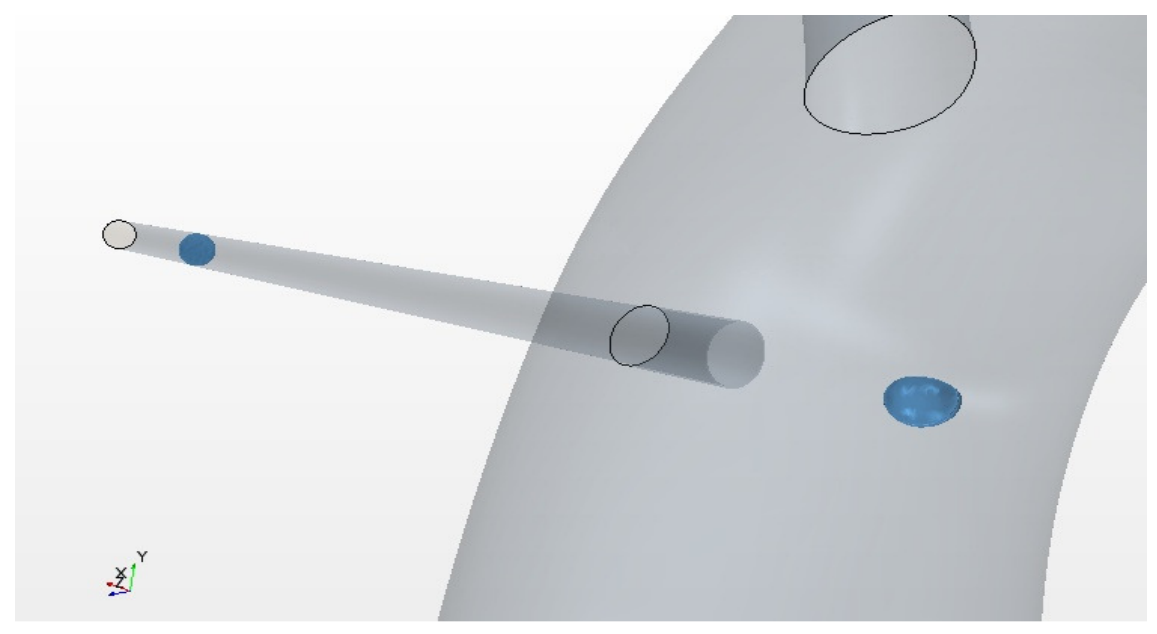

Figure $12.15^{\circ}$ case showing blue isosurface area of $600 \mathrm{~Pa}$, enough to damage $\mathrm{RBC}$

There is a secondary area within the cannula that shows an area of excessive stress. However, this area was present in each of the 5 cases and was attributed to flow development within the cannula, which is beyond the scope of this study. Further information can be found in Appendix B.

\subsection{Normal Stress}

The levels of normal stress can be seen in Table 2. Discuss further

Table 4. Max normal shear stress by case

\begin{tabular}{|c|c|}
\hline Angle Case $\left(^{\circ}\right.$ ) & Maximum Normal Stress (Pa) \\
\hline 60 & 215.72 \\
\hline 45 & 547.20 \\
\hline 30 & 1012.10 \\
\hline 15 & 1358.30 \\
\hline 0 & 333.61 \\
\hline
\end{tabular}

The higher levels of normal stress were exhibited in the $30^{\circ}-15^{\circ}$ range. By avoiding those areas, the risk of mobilizing an embolism would be attenuated. These results compared within a factor of 2 to related studies[11]. 


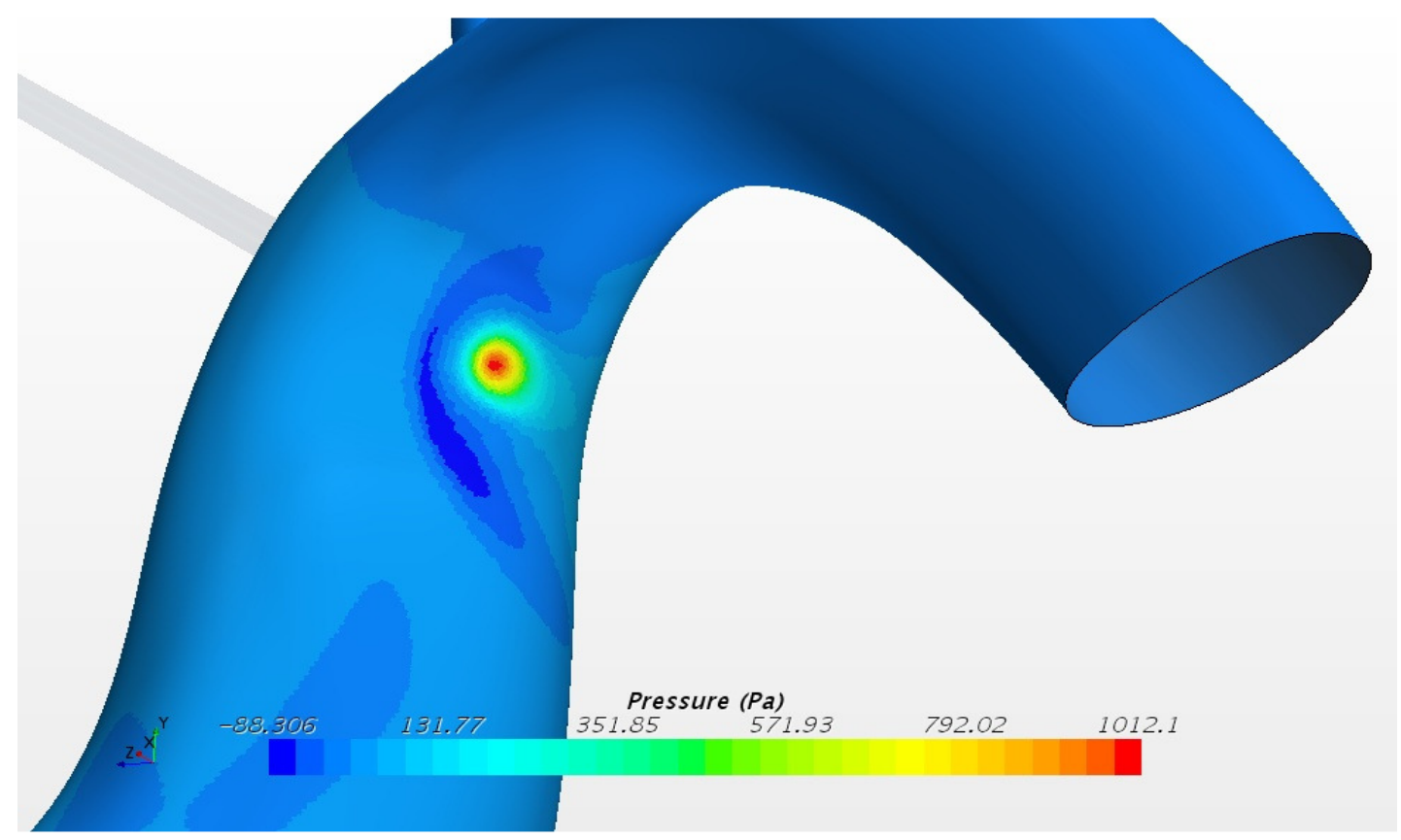

Figure $13.30^{\circ}$ case normal stress on wall of ascending aorta

Major considerations that create deviations from real world deal primarily with the lack of atherosclerotic deposition geometries in the aorta. The wall shear stress values would be significantly different, and a better exhibition of how deposits would react to viscous flow would be evident, were the deposits present. In this case, ideal geometries were studied.

\section{CONCLUSION AND FUTURE RESEARCH}

This study provides a general understanding of how modulating the angle of cannulation in the ascending aorta below the horizontal will affect fluid structure interaction within the aorta and flow development therein. Due to the variability in cannulation during CPB, general information of how the process will be affected by outflow cannula position and angulation are critical to avoid potentially life-threatening post-operative complications.

A three-dimensional computational fluid dynamics study was performed using smooth internal aorta geometry that included the supra-aortic arteries and the beginning of the descending aorta. Blood was approximated by simulating water and modifying the density to be within the known density region of blood. Systemic flow resistances inherent to the human body were estimated by iteratively solving a standard (non-CPB) flow case and modifying the simulated resistance pressures at the pressure outlet boundary conditions until the flow distributions met that of documented cardiac function studies. An $8 \mathrm{~mm}$ diameter outflow cannula was used to perfuse the ascending aorta in the horizontal or $0^{\circ}$ case and the angle was decreased in increments of $15^{\circ}$ to $60^{\circ}$ below horizontal in the frontal plane. Flow rates for the simulation were set to $3.7 \mathrm{l} / \mathrm{min}$. Turbulence was modeled using a two-layer realizable k-epsilon model. The flow rates of each supra-aortic artery and descending aorta were monitored, along with wall shear stress, normal stress, and intra-fluid shear stress. 
International Journal of Biomedical Engineering and Science (IJBES), Vol. 4, No. 2, April 2017

The study showed that $45^{\circ}$ to $60^{\circ}$ cannulation angles yield acceptable results related to flow distribution, wall shear stress, intra-fluid shear stress, and vascular normal stress. This does not factor geometric deviations due to atherosclerosis into account.

Further study of the phenomena would include changing the cannulation angle in the transverse plane in conjunction with angles in the frontal plane. The fluid used in this study was a water like fluid with a constant density to match that of blood flow, to study this further, modifications to viscosity could be made.

\section{REFERENCES}

1. G. S. Murphey, E. A. Hessel and R. C. Groom, "Optimal Perfusion during Cardiopulmonary Bypass: An Evidence-Based Approach," International Anesthesia Research Society, vol. 108, no. 5, pp. 1394$1417,2009$.

2. M. Minakawa, I. Fukuda, J. Yamazaki, K. Fukui, H. Yanaok and T. Inamura, "Effect of Cannula Shape on Aortic Wall and Flow Turbulence: Hydrodynamic Study using Extracorporeal Circulation in Mock Thoracic Aorta," Artificial Organs, vol. 31, no. 12, pp. 880-886, 2007.

3. M. Poullis, "Computation Fluid Dynamics Analysis to Prevent Aortic Root and Valve Clots During Left Ventricular Assist Device Support," The Journal of ExtraCorporeal Technology, vol. 44, pp. 210$215,2012$.

4. I. Avrahami, B. Dilmoney, A. Azuri, M. Brand, O. Cohen, L. Shani, R.-R. Nir and G. Bolotin, "Investigation of Risks for Cerebral Embolism Associated with the Hemodynamics of Cardiopulmonary Bypass Cannula: A Numeric Model," Artificial Organs, vol. 37, no. 10, pp. 857-865, 2013.

5. S. Demertzis, R. Trunfio, F. von Rotz and F. Siclari, "Surgical Approach in Massive Intraoperative Atherosclerotic Embolism," Annals of Thoracic Surgery, vol. 81, pp. 2298-2300, 2006.

6. P. G. Menon, J. F. Antaki, A. Undar and K. Pekkan, "Aortic Outflow Cannula Tip Design and Orientation Impacts Cerebral Perfusion During Pediatric Cardiopulmonary Bypass Procedures," Journal of Biometical Engineering, vol. 41, no. 12, pp. 2588-2602, 2013.

7. A. Finley and C. Greenberg, "Heparin Sensitivity and Resistance: Management During Cardiopulmonary Bypass," Anesthesia and Analgesia, vol. 116, no. 6, pp. 1210-1222, 2013.

8. T. A. Kaufmann and e. al, "The Impact of Aortic/Subclavian Outflow Cannulation for Cardiopulmonary Bypass and Cardiac Support: A Computational Fluid Dynamics Study," Artificial Organs, vol. 33, no. 9, pp. 729-732, 2009.

9. M. T. and e. al, "Supra Aortic Flow Distribution Measured with Phase Contrast MR Angiography," European Society of Radiology, pp. 1-17, 2012.

10. M. Grigioni, C. Daniele, G. D'Avenio and V. Barbaro, "A Discussion on the Threshold Limit for Hemolysis Related to Reynolds Shear Stress," Journal of Biomechanics, vol. 32, pp. 1107-1112, 1999.

11. Y. Tokuda, M.-H. Song, Y. Ueda, A. Usui, T. Akita, S. Yoneyama and S. Maruyama, "ThreeDimensional Numerical Simulation of Blood Flow in the Aortic Arch During Cardiopulmonary Bypass," European Journal of Cardio-Thoracic Surgery, vol. 33, pp. 164-167, 2008. 